International Journal of Current Advanced Research

ISSN: O: 2319-6475, ISSN: P: 2319 - 6505, Impact Factor: SJIF: 5.995

Available Online at www.journalijcar.org

Volume 6; Issue 4; April 2017; Page No. 3470-3473

DOI: http://dx.doi.org/10.24327/ijcar.2017.3473.0296

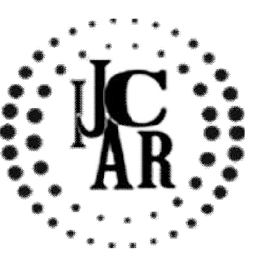

Research Article

\title{
USAGE OF LASER RAMAN SPECTROSCOPY TO INDENTIFY THE UNSTABLE COMPOUNDS OF IRON OXIDES
}

\author{
Nafie A. Almuslet*., Mubarak M. Ahmed and Siham M. Hassen
}

Department of laser systems, Institute of laser - Sudan University of Science and Technology

(www.sustech.edu), almogran - Khartoum / Republic of Sudan, P. O. Box (407)

\section{A R T I C L E I N F O}

\section{Article History:}

Received $10^{\text {th }}$ January, 2017

Received in revised form $20^{\text {th }}$ February, 2017

Accepted $22^{\text {nd }}$ March, 2017

Published online $28^{\text {th }}$ April, 2017

\section{Key words:}

Hematite, goethite, akaganeite, unstable compounds, laser Raman spectroscopy

\begin{abstract}
A B S T R A C T
In this work laser Raman Spectroscopy was used to identify the unstable compounds in three iron oxides. These samples were irradiated using $5 \mathrm{~mW}$ frequency doubled Nd-YAG laser with $532 \mathrm{~nm}$ at room temperature. Spectra database was used for the spectral analysis of the Raman shift of the three samples. The results obtained showed that the unstable compounds appeared in the spectra of the samples. Characteristic bands of hematite appeared in the spectra of goethite and akaganeite compounds while magnetite compounds appeared in the spectra of hematite. The laser power causes the bands to broaden and to undergo a small shift to lower wavenumbers. Other materials are appeared in spectra of the three samples like disulfide, alkyl disulfide and aliphatic fluoro. Raman spectroscopy proved to be suitable method for the identification of unstable compounds in hematite, goethite and akaganeite and could be used for other materials.
\end{abstract}

Copyright $\subseteq 2017$ Nafie A. Almuslet et al. This is an open access article distributed under the Creative Commons Attribution License, which permits unrestricted use, distribution, and reproduction in any medium, provided the original work is properly cited.

\section{INTRODUCTION}

Raman spectroscopy is a spectroscopic technique used in condensed matter physics and chemistry to study vibrational, rotational and other low-frequency modes in a system [1]. It depends on the scattering phenomenon. In this context, scattering occurs due to collisions between photons and molecules. Generally, a photon collides with a substance, not necessarily only with a molecule. Irradiation of light with the frequency $\mathrm{v}_{0}$ upon a certain molecule brings a number of photons with the energy $\mathrm{E}=\mathrm{hv}_{0}$ to this molecule. Most photons colliding with molecules do not change their energy after the collision (elastic collision) and the ensuing radiation is called Rayleigh scattering. Rayleigh scattering consists of photons that have the same frequency as the incident light. A very small number of the photons that collide with the molecules exchange energy with them upon the collision (an example of in elastic collision). If an incident photon delivers an $\mathrm{hv}_{0}$ quantum of energy to the molecule, the energy of the scattered photon reduces to $h\left(v_{0}-v\right)$ and the frequency of the scattering photon becomes $\left(\mathrm{v}_{0}-\mathrm{v}\right)$. On the contrary, when an incident photon receives the hv energy from the molecule, the energy of the scattering photon rises to $h\left(v_{0}+v\right)$, and the frequency of the scattering photon becomes $\left(\mathrm{v}_{0}+\mathrm{v}\right)$. Scattering in which an incident photon exchanges energy with a molecule is known as Raman scattering [2].

*Corresponding author: Nafie A. Almuslet

Department of laser systems, Institute of laser - Sudan University of Science and Technology (www.sustech.edu), almogran -

Khartoum / Republic of Sudan, P. O. Box (407)
Scattered light having the frequency of $\mathrm{v}_{0}-\mathrm{V}$ and that having the frequency of vibration $\mathrm{v}_{0}+\mathrm{v}$ are called "Stokes Raman scattering" and "anti-Stokes Raman scattering", respectively. Stokes Raman scattering arises from interaction between a photon and a molecule that is in the ground state, while anti-Stokes Raman scattering is due to interaction between a photon and a molecule that is in the excited state [2]. At ambient temperatures, most molecular vibrations are in the ground state and thus the anti-Stokes transitions are less likely to occur than the Stokes transitions, resulting in the Stokes Raman scattering being more intense. For this reason, it is usually the Stokes Raman spectrum that is routinely studied [3]. Actually it is the finger print of the molecule so it can be used to identify different materials. This work aimed to use Raman Spectroscopy to identify the unstable compounds of three types of the iron oxides.

\section{MATERIALS AND METHODS}

Three samples of hematite, goethite and akaganeite, were investigated in this work by laser Raman spectrometer in the range from $400 \mathrm{~cm}^{-1}$ to $4500 \mathrm{~cm}^{-1}$.

\section{Equipments}

In this work laser Raman microscope spectrometer model Burker sentrra, shown in the Figure (1) was used. The light source of this spectrometer is Nd-YAG laser with wavelength of 532 and output power of $5 \mathrm{~mW}$. The Raman shift in wave number, and the change in intensities in of the scattered light were compared with data in the references and previous studies. 


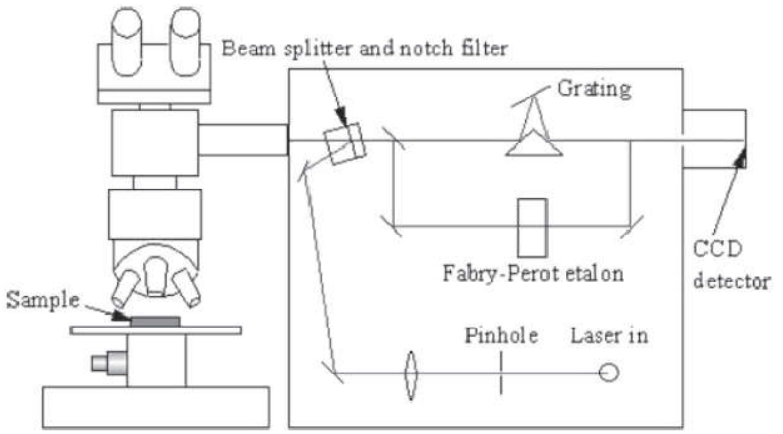

Figure 1 schematic diagram of Burker sentrra laser Raman microscope spectrometer.

\section{Samples preparation}

Samples were prepared as follows

\section{Sample1: Hematite $\left(\mathrm{Fe}_{2} \mid \mathrm{O}_{3}\right)$}

Fourty grams of Ferric nitrate $\left(\mathrm{Fe}\left(\mathrm{NO}_{3}\right)_{3} .9 \mathrm{H}_{2} \mathrm{O}\right)$ was dissolved in $500 \mathrm{ml}$ of twice distilled water in polyethylene flask. Then , $300 \mathrm{ml}$ of one molar (1M) potassium hydroxide $(\mathrm{KOH})$ was added to the flasked followed by $50 \mathrm{ml}$ of one molar $(1 \mathrm{M})$ sodium bicarbonate $\left(\mathrm{NaHCO}_{3}\right)$. The mixtures were heated to $90 \mathrm{C}^{0}$, till formation of red brown precipitates of ferrihydrite. The flask and the content was allowed to stand for 48 hours. During this time the red brown suspension of ferrihydrite transformed to hematite with $\mathrm{pH}$ of 8 to 8.5 [4].

\section{Sample2: Goethite $(\alpha \mathrm{FeOOH})$}

$100 \mathrm{ml}$ of one molar $(1 \mathrm{M})$ Ferric nitrate $\left(\mathrm{Fe}\left(\mathrm{NO}_{3}\right)_{3}\right.$ solution was added into 2 liter polyethylene flask, then 180 $\mathrm{ml}$ of five molar $(5 \mathrm{M})$ potassium hydroxide $(\mathrm{KOH})$ was added rapidly with stirring, till formation of Red brown precipitates of ferrihydrite at once. The suspension was diluted with twice stilled water and holded in a closed polyethylene flask maintained at $70 \mathrm{C}^{0}$ in an oven for $60 \mathrm{~h}$. At the end of this period of time the red-brown suspension of ferrihydrite transformed in to a compact yellow precipitate of goethite [5].

\section{Sample 3: Akaganeite $(\mathrm{BFeOOH})$}

0.1 molar $(0.1 \mathrm{M})$ of $\mathrm{FeCl}_{3}$ solutions hold in to 2 liter in closed vessel at $70 \mathrm{C}^{0}$ for $48 \mathrm{~h}$. During this time the $\mathrm{pH}$ of the system drops from 1.7 to 1.2 and compact yellow precipitate of akaganeite was formed [5].

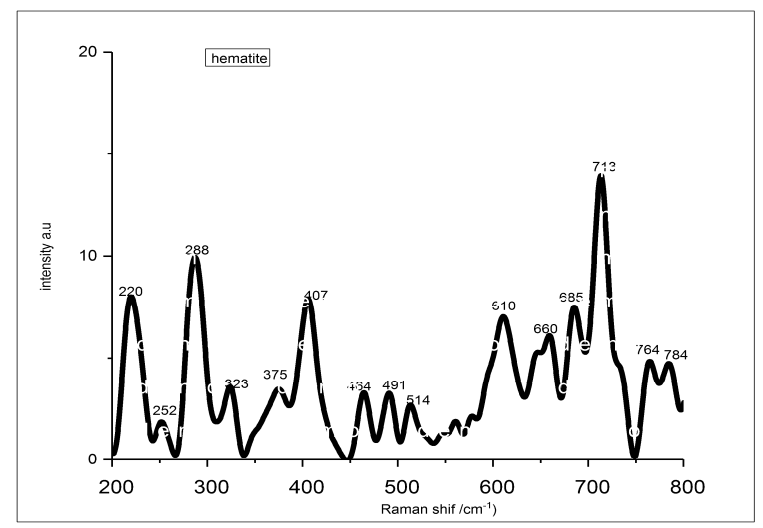

Figure 2 Raman spectrum of hematite in the range from $2008-00 \mathrm{~cm}^{-1}$

\section{RESULTS AND DISCUSSION}

Figure (2) shows the Raman spectrum of hematite after irradiation with Nd-YAG laser with wavelength of $532 \mathrm{~nm}$ and $5 \mathrm{~mW}$ output power. The spectrum shows clear peaks and by comparison with the vibrations recorded in some references we found that these vibrations are attributed to hematite compounds beside unstable components of hematite and some components of materials that are listed in table (1).

Table 1 The analyzed data of Raman spectrum of the hematite

\begin{tabular}{cccc}
\hline $\begin{array}{c}\text { Raman shift } \\
\left(\mathbf{c m}^{-1}\right)\end{array}$ & $\begin{array}{c}\text { Intensity } \\
(\mathbf{a . u})\end{array}$ & Assignment & references \\
\hline 220 & 8.51 & FeII-O & {$[10,11]$} \\
252 & 2.8 & FeII-O & {$[10,11.12]$} \\
288 & 10.7 & FeII-O & {$[10,11]$} \\
323 & 4.6 & FeIII-O & {$[15]$} \\
375 & 4.85 & Se-Se & {$[6,7,8]$} \\
407 & 8.07 & FeII-O & {$[10,11]$} \\
464 & 4.31 & Si-O-Si & {$[6,7,8,9]$} \\
491 & 4.36 & FeII-O & {$[10,11,12]$} \\
514 & 3.09 & S-S & {$[6,7,8]$} \\
610 & 7.3 & FeII-O & {$[13]$} \\
660 & 6.26 & FeIII-O & {$[14]$} \\
685 & 7.8 & C=S & {$[6,7,8]$} \\
713 & 14.1 & FeIII-O & {$[13]$} \\
764 & 5.0 & C-F & {$[6,7]$} \\
784 & 5.2 & C-F & {$[6,7]$} \\
\hline
\end{tabular}

Figure (3) shows the Raman spectrum of goethite after irradiation with Nd-YAG laser with wavelength of $532 \mathrm{~nm}$ and $5 \mathrm{~mW}$ output power. The vibrations of goethite are appeared in the spectrum beside the vibrations of unstable components of goethite beside other materials. These vibrations are consistent with many previous studies as listed in table (2)

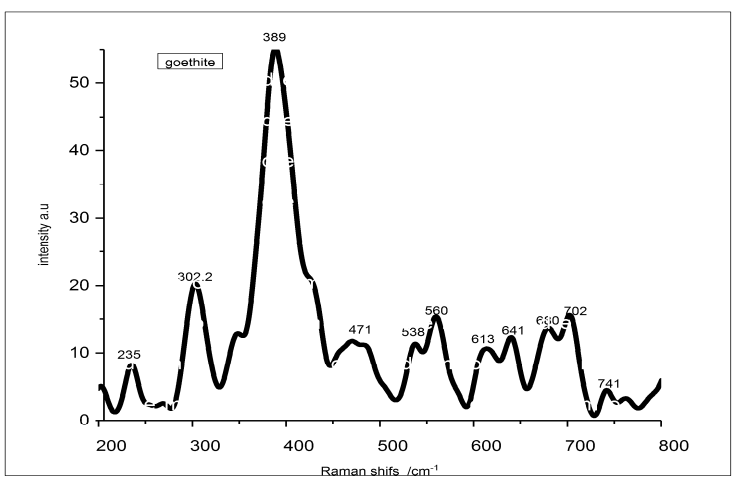

Figure 3 Raman spectrum of goethite in the range from 200 to 800 $\mathrm{cm}^{-1}$

Table 2 The analyzed data of Raman spectrum of the goethite

\begin{tabular}{cccc}
\hline $\begin{array}{c}\text { Raman shift } \\
\left(\mathbf{c m}^{-1}\right)\end{array}$ & $\begin{array}{c}\text { Intensity } \\
(\mathbf{a . u})\end{array}$ & Assignment & References \\
\hline 235 & 10.6 & $\alpha \mathrm{Fe}-\mathrm{OH}$ & {$[5,14]$} \\
302.2 & 23.4 & $\alpha \mathrm{Fe}-\mathrm{OH}$ & {$[5,14]$} \\
389 & 56 & $\alpha \mathrm{Fe}-\mathrm{OH}$ & {$[5,14]$} \\
471 & 14,8 & $\alpha \mathrm{Fe}-\mathrm{OH}$ & {$[5,14]$} \\
538 & 14.4 & $\mathrm{Si}-\mathrm{O}-\mathrm{Si}$ & {$[6,7,8,9]$} \\
560 & 16.0 & $\alpha \mathrm{Fe}-\mathrm{OH}$ & {$[5,14]$} \\
613 & 13.7 & $\mathrm{FeII}-\mathrm{O}$ & {$[10]$} \\
641 & 15.3 & $\mathrm{C}=S$ & {$[6,7,8]$} \\
680 & 15.7 & $\alpha \mathrm{Fe}-\mathrm{OH}$ & {$[14]$} \\
702 & 18.2 & $\mathrm{FeII}-\mathrm{O}$ & {$[16]$} \\
741 & 6.8 & $\mathrm{C}-\mathrm{F}$ & {$[6,7]$} \\
\hline
\end{tabular}


Figure (4) shows the Raman spectrum in the range from 200 to $800 \mathrm{~cm}^{-1}$ of akaganeite. The vibrations of akaganeite are appeared in spectrum beside some unstable components and some other materials. These vibrations are consistent with many previous studies as listed in table (3).

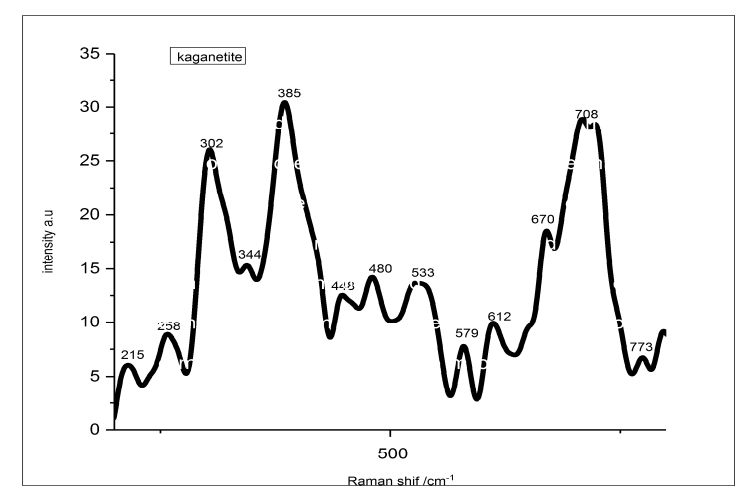
Figure 4 Raman spectrum of akaganeite in the range from $200-800$

Table 3 The analyzed data of Raman spectrum of the akaganeite

\begin{tabular}{cccc}
\hline $\begin{array}{c}\text { Raman shift } \\
\left(\mathbf{c m}^{-1}\right)\end{array}$ & $\begin{array}{c}\text { Intensity } \\
(\mathbf{a . u})\end{array}$ & Assignment & References \\
\hline 215 & 8.6 & FeII-O & {$[[10,11]$} \\
258 & 11.3 & FeII-O & {$[10]$} \\
302 & 26.3 & $\beta \mathrm{FeOOH}$ & {$[5,13]$} \\
385 & 30.6 & $\beta \mathrm{Fe}-\mathrm{OH}$ & {$[5,13]$} \\
344 & 17.2 & $\mathrm{Se}-\mathrm{Se}$ & {$[6,7,8,9]$} \\
448 & 14 & $\mathrm{~S}-\mathrm{S}$ & {$[6,7,8,9]$} \\
480 & 16.1 & $\beta \mathrm{Fe}-\mathrm{OH}$ & {$[13]$} \\
533 & 16 & $\beta \mathrm{Fe}-\mathrm{OH}$ & {$[13]$} \\
579 & 10.34 & $\mathrm{C}=S$ & {$[6,7,8,9]$} \\
612 & 11.15 & $\beta \mathrm{Fe}-\mathrm{OH}$ & {$[13]$} \\
670 & 20.5 & $\beta \mathrm{Fe}-\mathrm{OH}$ & {$[13]$} \\
708 & 29.3 & $\beta \mathrm{Fe}-\mathrm{OH}$ & {$[5,13]$} \\
773 & 8.31 & $\mathrm{C}-\mathrm{F}$ & {$[6,7]$} \\
\hline
\end{tabular}

Through the analysis of the three samples it was found that the vibration modes of some materials are appeared as follows:

1. FeII-O appeared in the spectra of the three samples at different intensities $(10.7,8.51,2.8,8.07,4.36,7.3$, $13.7,18.2,8.6,11.3)$.

2. FeIII-O appeared in the spectrum of the hematite at different intensities $(4.6,6.26,14.1)$.

3. $\alpha \mathrm{Fe}-\mathrm{OH}$ appeared in the spectrum of the goethite with different intensities $(10.6,23.4,56,14.8,16,15.7)$.

4. $\beta \mathrm{Fe}-\mathrm{OH}$ appeared in the spectrum of the akaganeite with different intensities $(26.3,30.6,16.1,16,11.15$, 20.5, 29.3).

5. $\mathrm{Si}-\mathrm{O}-\mathrm{Si}$ appeared in the spectra of the hematite and goethite samples with different intensities $(4.31,4.4)$.

6. $\mathrm{C}=\mathrm{S}$ appeared in the spectra of the three samples with different Intensities (7.8, 15.3, 10.34).

7. Se-Se appeared in the spectra of hematite and akaganeite with different Intensities $(4.85,17.2)$.

8. S- S appeared in the spectra of the hematite and akaganeite with different intensities $(3.09,14)$.

9. C-F appeared in the spectra of the three samples with different intensities (5.0, 5. 2, 6.8, 8.31).

The bands that proved to be useful for the identification of the investigated hematite are listed in Tables (1). Six vibration modes of FeII-O at 288, 220, $407 \mathrm{~cm}^{-1}, 491,610$ and
$252 \mathrm{~cm}^{-1}$ are mentioned with the literatures (Thibeau et al. 1978, De Faria et al. 1997), [ 10,11]. Also vibrational modes at $713 \mathrm{~cm}^{-1}, \quad 660 \mathrm{~cm}^{-1}$ and $323 \mathrm{~cm}^{-1}$ were observed. These are assigned to Magnetite and this agreed with the results of other research (Shebanova ON et al. 2003, Oh et al. 1998) $[13,14]$. Vibration modes of other materials are observed at $464 \mathrm{~cm}^{-1}$ and assigned to silicate, $685 \mathrm{~cm}^{-1}$ assigned to alkyl sulfides, $514 \mathrm{~cm}^{-1}$ assigned to dialkyl disulfide, 774 $\mathrm{cm}^{-1}$ and $784 \mathrm{~cm}^{-1}$ which are assigned to Aliphatic fluoro according to [6.7.8.9].

In the Raman spectrum of Goethite high intensity vibrational modes of $\alpha \mathrm{Fe}-\mathrm{OH}$ are appeared at $389 \mathrm{~cm}^{-}$ $1,235,302.2,389,471,560$ and $681 \mathrm{~cm}^{-1}$ and are assigned to goethite as mentioned in the literatures (Oh et al. 1998) [14 ] . Also we found vibrations mode of FeII$\mathrm{O}$ that appeared in the spectra at 702 and $613 \mathrm{~cm}^{-1}$ and assigned to hematite and mentioned in the literatures (Thibeau et al. a 1978, De Faria al. a 1997), [10,11]. Other vibration modes at $538 \mathrm{~cm}^{-1}$ and assigned to silicate, vibration mode at $641 \mathrm{~cm}^{-1}$ attributed to alkyl disulfide and mode at 741 assigned to aliphatic fluoro and those findings agreed with the results of other research's [6.7.8.9]. For akaganeite, seven vibration modes of $\beta \mathrm{Fe}-\mathrm{OH}$ appeared at $302,385,708 \mathrm{~cm}^{-1}, 490,533,612$ and 670 $\mathrm{cm}^{-1}$ are assigned to akaganeite as presented in the literatures (Oh et al.1998), [14]. In addition vibration modes at 215 and $258 \mathrm{~cm}^{-1}$ are recorded which attributed to hematite according to (Thibeau et al. a 1978, De Faria al. a $1997),[10,11]$. Other vibration modes were observed at $448 \mathrm{~cm}^{-1}$ and assigned to dialkyl disulfide, $579 \mathrm{~cm}^{-1}$ and assigned to alkyl disulfide, $773 \mathrm{~cm}^{-1}$ and assigned to aliphatic fluoen according to $[6,7,8,9]$.

\section{CONCLUSIONS}

The results presented in this work show that Raman spectroscopy technique is an efficient method to identify unstable compounds of hematite, goethite and akaganeite. It provides precise information about other materials found in the three samples.

\section{References}

1. Sur UK. Surface-enhanced raman scattering (SERS) spectroscopy: a versatile tool in electrochemistry. Research \& Reviews in Electrochemistry. 2013;4(3).

2. Ekins S. Pharmaceutical applications of Raman spectroscopy. Sasic S, editor. John Wiley \& Sons; 2008 Feb 15.

3. Wartewig S. IR and Raman spectroscopy: fundamental processing. John Wiley \& Sons; 2006 Mar 6.

4. Schwertmann U, Cornell RM. Iron oxides in the laboratory: preparation and characterization. John Wiley \& Sons; 2008 Sep 26.

5. Cornell RM, Schwertmann U. The iron oxides: structure, properties, reactions, occurrences and uses. John Wiley \& Sons; 2003 Oct 17.

6. Edwards HG. Modern Raman spectroscopy-a practical approach. Ewen Smith and Geoffrey Dent. John Wiley and Sons Ltd, Chichester, 2005. Pp. 210. ISBN 0471 496685 (cloth, hb); 0471497940 (pbk).

7. Robert MS, Francis XW, David JK. Spectrometric identification of organic compounds. John wiley \& Sons, Inc, Hoboken, edn. 2005;7:106. 
8. Manoharan R, Sethi N. 8.51 Raman Analyzers.

9. Socrates G. Infrared and Raman characteristic group frequencies: tables and charts. John Wiley \& Sons; 2004 Jun 18.

10. Thibeau RJ, Brown CW, Heidersbach RH. Raman spectra of possible corrosion products of iron. Applied Spectroscopy. 1978 Nov; 32(6):532-5.

11. De Faria DL, Venâncio Silva S, De Oliveira MT. Raman microspectroscopy of some iron oxides and oxyhydroxides. Journal of Raman spectroscopy. 1997 Nov 1; 28(11):873-8.

12. Hanesch M. Raman spectroscopy of iron oxides and (oxy) hydroxides at low laser power and possible applications in environmental magnetic studies. Geophysical Journal International. 2009 Jun 1; 177(3):941-8.
13. Shebanova ON, Lazor P. Raman spectroscopic study of magnetite (FeFe $2 \mathrm{O}$ 4): a new assignment for the vibrational spectrum. Journal of Solid State Chemistry. 2003 Sep 30; 174(2):424-30.

14. Oh SJ, Cook DC, Townsend HE. Characterization of iron oxides commonly formed as corrosion products on steel. Hyperfine interactions. 1998 Dec 1; 112(1-4):5966.

15. Legodi MA. Raman spectroscopy applied to iron oxide pigments from waste materials and earthenware archaeological objects (Doctoral dissertation, University Of Pretoria Pretoria).

16. Legodi MA, De Waal D. The preparation of magnetite, goethite, hematite and maghemite of pigment quality from mill scale iron waste. Dyes and Pigments. 2007 Dec 31;74(1):161-8.

\section{How to cite this article:}

Nafie A. Almuslet et al (2017) ' Usage Of Laser Raman Spectroscopy To Indentify The Unstable Compounds Of Iron Oxides', International Journal of Current Advanced Research, 06(04), pp. 3470-3473.

DOI: http://dx.doi.org/10.24327/ijcar.2017.3473.0296 